\title{
Aluminum Recovery from White Aluminum Dross by a Mechanically Activated Phase Separation and Remelting Process
}

\author{
ARTUR KUDYBA (i) ${ }^{1,3}$ SHAHID AKHTAR, ${ }^{2}$ INGE JOHANSEN, ${ }^{2}$ \\ and JAFAR SAFARIAN ${ }^{1}$ \\ 1.--Norwegian University of Science and Technology (NTNU), Alfred Getz Vei 2, Trondheim, Norway. \\ 2.-Hydro Aluminum, Sunndalsøra, Norway. 3.—e-mail: artur.kudyba@ntnu.no
}

The aluminum recovery from white aluminum dross by a mechanical treatment and sizing followed by remelting process was investigated. The dross was subjected to a ball mill, and the obtained particles were sized in different ranges. They were studied by advanced materials characterization techniques. It was found that the larger particles contain high metallic portions, and most non-metallic components of the dross are in the fine fraction $<1 \mathrm{~mm}$. The Alrich particles $(>1 \mathrm{~mm})$ were remelted at $900^{\circ} \mathrm{C}$ to recover aluminum. It was found that the metal structure after remelting is homogeneous and consisted of a dominant metallic aluminum matrix, containing an average of $>96 \% \mathrm{Al}$ with around $99 \%$ total metallic components. The results show that the applied method is a good economic alternative for the aluminum recovery from white dross, which is important for the valorization/recycling of industrial waste and circular economy.

\section{INTRODUCTION}

Aluminum is the most abundant metallic element in the earth's crust, posing an excellent combination of chemical, mechanical and physical properties, which makes it suitable for many engineering applications. It makes up about $8 \%$ by weight of the earth's solid surface, and it never occurs as a free element in nature. ${ }^{1}$ Aluminum is produced via two different routes: a primary aluminum production from bauxite ore by the Bayer process for alumina extraction followed by the Hall-Heroult electrolysis for $\mathrm{Al}$ extraction from alumina and by recycling aluminum from process scrap and used aluminum products. ${ }^{1,2}$ The world production of metallic aluminum in 2019 was approximately 64 million metric tons with a daily average of 174.5 thousand tons. ${ }^{3}$ During the process of melting and alloying, molten aluminum meets the oxidizing atmosphere; therefore, a surface oxidation takes place, leading to the formation of a semisolid skin over the molten metal. This mixture, called

(Received December 26, 2020; accepted May 12, 2021;

published online June 2, 2021) aluminum dross, essentially consists of aluminum oxide, metallic aluminum, magnesium spinel $\left(\mathrm{MgAlO}_{4}\right)$, periclase $(\mathrm{MgO})$, quartz $\left(\mathrm{SiO}_{2}\right)$ and salts with small traces of aluminum carbides and nitrides. ${ }^{4}$ The recycling of $\mathrm{Al}$ dross, which is a byproduct obtained during production of aluminum and its alloys, is important from both the environmental protection and economic points of view. ${ }^{1,2}$ Generally, there are two types of $\mathrm{Al}$ dross: (1) white dross (the primary dross) and (2) black dross (the secondary dross). White dross is formed during the primary production of aluminum and contains a high percentage of an aluminum substance such as $\mathrm{Al}, \mathrm{Al}_{2} \mathrm{O}_{3}$, and it is delivered from essential and optional aluminum flux. White dross consists of a greater amount of metallic aluminum substance, i.e., 15 to $75 \%$ and $<5 \%$ salts. It consists of fine powder separated from the liquid aluminum. ${ }^{5}$ Black dross consists of a small amount of metal substance and is created at the time of the secondary aluminum refining processes. Black dross involves a mix of aluminum oxides and slag, with recoverable aluminum content in the range of $12 \%-18 \%$. More salt substance, e.g., $>40 \%$, stood out from the white dross. $^{5-10}$ Aluminum dross is a potential toxic 
industrial waste inevitably generated in aluminum smelter plants. The safe disposal of $\mathrm{Al}$ dross as a waste is a burden to the aluminum industry because improper disposal affects the eco-system by contaminating surface and ground water. Aluminum dross in contact with water (e.g., during a rainfall) produces hazardous gases such as phosphine and ammonia, polluting the atmosphere. The contamination of soil and groundwater with heavy metals existing in $\mathrm{Al}$ dross storage areas is also evident. The worldwide aluminum industry produces nearly 4 million tons of aluminum white dross (AWD) ${ }^{8}$. More than a million tons of aluminum black dross (ABD) are reported worldwide each year, and around $95 \%$ of this material is landfilled. ${ }^{1,11}$ The presence of toxic materials in aluminum dross aggravates the environmental crisis, whereas the metallic aluminum entrapped in the alumina matrix could be used as a raw material for the metal extraction processes ${ }^{12-15}$. Primary smelters usually produce white dross with higher percentages of metallic content (15\%-80\%), because the raw material for smelting is mainly aluminum ingots and primary aluminum from electrolysis cells. When the metallic aluminum content in the white dross is $>$ $53 \%$, granular dross particles tend to be formed. ${ }^{4}$ In the case of lower metallic content, the formation of oxide is predominant. ${ }^{6}$ Owing to the large annual production of $\mathrm{Al}$ dross and its environmental and economic impacts, proper recycling and utilization of aluminum dross is crucially important.

Aluminum dross undergoes industrial treatments to extract valuable products, including metallic aluminum. Basically, two methods of $\mathrm{Al}$ dross treatment are used: (1) pyrometallurgical, which is a conventional method of treating $\mathrm{Al}$ dross, liberating metallic aluminum in the liquid state, and (2) hydrometallurgical, which involves an extraction of metallic aluminum from the $\mathrm{Al}$ dross by converting it into aluminum salts and compounds. The metal extraction using the pyrometallurgical process gives a good metal recovery rate. In the case of lower metallic content in the dross, the hydrometallurgical process is preferred. ${ }^{15}$ However, for the recycling, utilization and extraction of the metallic aluminum, it is necessary to carry out a preprocessing of aluminum dross. The first stage of the pre-processing treatment is cooling down the hot dross followed by crushing, grinding and downsizing. After skimming, the hot dross is subjected to mechanical agitation, thus liberating liquid metal. The solid residue left over is crushed, sorted, ground and milled for a further recovery of metallic aluminum. After these mechanical operations, approximately $30 \%-50 \%$ of metallic content remains in the dross. ${ }^{16,17}$ Homogenization of ground particles allows a relatively easy extraction of metal. Further processing thereby liberates the metallic content entrapped in the matrix to some extent. This amount of metal can be subsequently separated by physical methods. For the rest of the extractable metallic percentage, pyrometallurgical or hydrometallurgical treatment is adopted. ${ }^{15}$

There are several different pyrometallurgical methods for extracting metallic aluminum from white $\mathrm{Al}$ dross. A salt fluxing for metal recovery is the conventional method, whereas the newly developed technologies utilize plasma arc rotary furnaces. ${ }^{18}$ Rotary salt furnaces (RSF) are oil- or gasfired furnaces charged with aluminum dross with salt flux of about 50\% that of the dross weight. However, the newly designed salt-free furnaces consume minimal or nearly no salt fluxes to recover metallic aluminum. ${ }^{15}$ Molten flux initiates and controls the destruction of the aluminum oxide network with aluminum trapped inside. Salt oxide interaction is enhanced as the rotation of the furnace is begun. ${ }^{19}$ Breakage of the continuous network leads to coalescence of aluminum drops, which sink to the aluminum bath, while aluminum oxides develop a chain-like structure having high specific area that traps metallic aluminum. This metallic portion is released when the molten salt is introduced to the surface of aluminum oxides, attacking the links and causing a discharge of aluminum. ${ }^{15}$ The salt-free technologies used for processing and recycling aluminum dross are mainly based on plasma technology. This process is mainly based on using a plasma torch to provide the heat for melting the charge in the rotary furnace. A controlled atmosphere of the furnace is always maintained to minimize oxidation of the metal. High voltage applied across the electrodes establishes an electric arc. Gradual rotation of the furnace while operating results in rupture of the oxide layer, leading to better extraction of aluminum and leaving behind a non-metallic product (NMP) as the residue. ${ }^{20-22}$

Hydrometallurgical treatment, such as pyrometallurgical, also provided extensive results in dross recycling, making hydrometallurgy an economically viable alternative means for treatment of $\mathrm{Al}$ dross. Due to the type of leaching solution used, hydrometallurgical processes can be divided into alkaline leaching and acid leaching. They consist of the separation of aluminum ions from either the alkaline or acidic leaching solutions used in the process. Alteration in media, such as alkali media and acidic media, along with leaching parameter variations, such as time and temperature, provides a variety of results. Hydrometallurgical treatment is mainly used for the processing and recycling of black dross (secondary dross) by-products of the secondary production of aluminum. ${ }^{23-27}$

The main purpose of the present work is to experimentally examine the feasibility of mechanical processing for the recycling of white aluminum dross through dross beneficiation and classification. Metallic $\mathrm{Al}$ recovery from the white dross by a mechanically activated phase separation via the conventional ball milling technique and further 
classification and remelting of the separated phases are carried out and characterized. The first mention of crushing as a method to separate aluminum metal from $\mathrm{Al}$ dross was by Gills (Patent GB $114,204 \mathrm{~A})^{28}$ in 1918 as part of a larger process to fully treat white drosses. The next patent (US $3,037,711)^{29}$ devoted entirely to liberation of aluminum metal by crushing and grinding was issued in 1962 to Businger of Metallwerke Refonda, Weiderkehr \& Co. for a dry milling process which uses a mill to flatten aluminum pieces that are then separated from the friable oxides by screening and air classification. ${ }^{30}$ A literature survey ${ }^{31-34}$ revealed a few works on crushing and milling as a method to separate aluminum metal. However, in the literature, there are a limited number of studies on the metallographic characterization of the dross phase separations and the size fractions after milling. ${ }^{31-34}$ Moreover, in the literature the results are described using milling treatment of dross combined with salts, such as Nguyen et al. ${ }^{31}$, who investigated the effect of a process consisting of ball milling followed by $\mathrm{NaOH}$ leaching to selectively dissolve alumina from black dross. These studies were all on black dross treatment, and it caused low $\mathrm{Al}$ recovery as a portion of metallic $\mathrm{Al}$ was lost in the process. Recoveries of $35 \%^{31}, 28.42 \%$ and $24.34 \%^{32}$, and $34 \%^{34}$ have been achieved. The present study, however, is focused on developing a salt-free integrated process to treat white dross; it includes mechanical treatment, followed by Al-rich portion separation and remelting. In all the former studies, no significant work was done on the Al-dross microstructure and the effect of mechanical treatment in a ball milling process, specifically on the different sizes of particles. Hence, the novelties of the present study are (1) providing microstructural information and the effect of mechanical treatment on it and (2) evaluating the possibility of Al-rich particle separation and (3) salt-free remelting to recover Al metal. The applied approach in the present work in principle initiates research on developing a salt-free process for $\mathrm{Al}$ recovery from white dross.

\section{EXPERIMENTAL PROCEDURE}

\section{Materials and Sampling}

An $\mathrm{Al}$ dross sample was directly taken from the surface of a molten Al-Si-Mn alloy (grade series 4000) having 88.6 wt.\% $\mathrm{Al}, 10.3$ wt.\% $\mathrm{Si}$ and 0.5 wt.\% Mn. The detailed chemical composition is given in supplementary Table S1. To directly extract a representative $\mathrm{Al}$ dross sample from the surface of the molten alloy, a special sampling tool was designed and developed (Fig. 1a).

Initially, the sampling tool was introduced into a dross tub, and when the $\mathrm{Al}$ dross was skimmed from the reverberatory furnace into the tub in which the tool was positioned, a portion of the hot dross was collected by the sampling unit (Fig. 1b). Samples of
$\mathrm{Al}$ dross for further analyses were then taken from three different positions of the collected sample, namely from the upper, middle and bottom parts of the dross.

\section{Mechanical Phase Separation}

The Al dross sample taken directly from the surface of molten Al-Si-Mn alloy was subsequently subjected to a mechanically activated phase separation by a milling technique at room temperature utilizing a ball mill (see supplementary Fig. S2). The authors use the term "activated" here as they believe that the technique will provide conditions to change the shape of the metallic component and is effective for the separation of non-metallic components or inclusions. A ball mill with dimensions of $28 \mathrm{~cm}$ was used for mechanical treatment. Steel balls with a total mass that was 2.6 times that of the added $\mathrm{Al}$ dross mass were applied. The milling time was $3 \mathrm{~h}$ and rotation speed of the milling chamber was $35 \mathrm{rpm}$. After milling, the total mass of $\mathrm{Al}$ dross was measured and indicated a mass loss of $0.6 \%$, mainly via fine dust formation and loss over the chamber and steel balls. This process was applied two times on the $\mathrm{Al}$ dross under the same conditions (milling time, rotation speed).

After the milling process, the milled product was fractioned by sieving through six sieves with mesh sizes of $\geq 10 \mathrm{~mm}, 4 \mathrm{~mm}, 2 \mathrm{~mm}, 1.25 \mathrm{~mm}, 1 \mathrm{~mm}$ and $\leq$ $1 \mathrm{~mm}$. Metallographic samples were prepared from samples of all sizes, and the samples were further characterized by using Zeiss Ultra 55 scanning electron microscopy (SEM) coupled with energydispersive x-ray spectroscopy (EDS). Moreover, for the sample below $1 \mathrm{~mm}$, XRD analysis was possible and was applied to characterize the phases.

\section{Remelting of Al-Rich Samples}

Individual fractions of the $\mathrm{Al}$ dross after milling and sieving were placed in alumina crucibles and then were subjected to remelting at $900^{\circ} \mathrm{C}$ for $1 \mathrm{~h}$ in a flow protective gas (Ar 5.0) at a pressure value of 1030 mbar in an induction furnace (see supplementary Fig. S3).

The macroscopic changes of the particles were studied. Moreover, the microstructural and chemical changes in the completely melted parts of samples were studied to evaluate the process. The structure and chemical composition were characterized by using Zeiss Ultra 55 scanning electron microscopy (SEM) coupled with energy-dispersive $\mathrm{x}$ ray spectroscopy (EDS).

\section{RESULTS AND DISCUSSION}

\section{Characteristics of the Al Dross}

The results of structural and chemical analysis of the $\mathrm{Al}$ dross by SEM and EDS are shown in Fig. 2. To identify the samples and distribution of elements, the three samples (upper, middle and bottom 


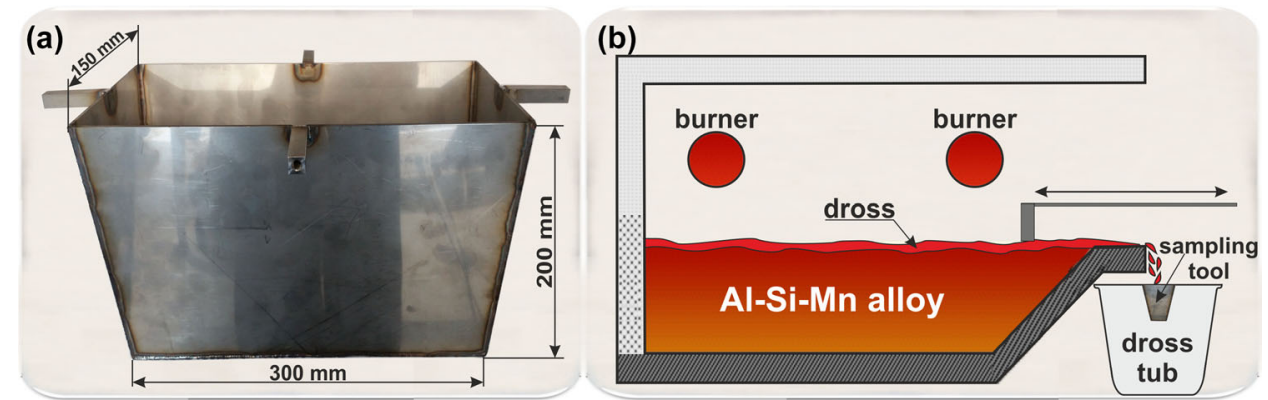

Fig 1. (a) A dedicated sampling tool; (b) sample collection procedure from the skimmed dross.
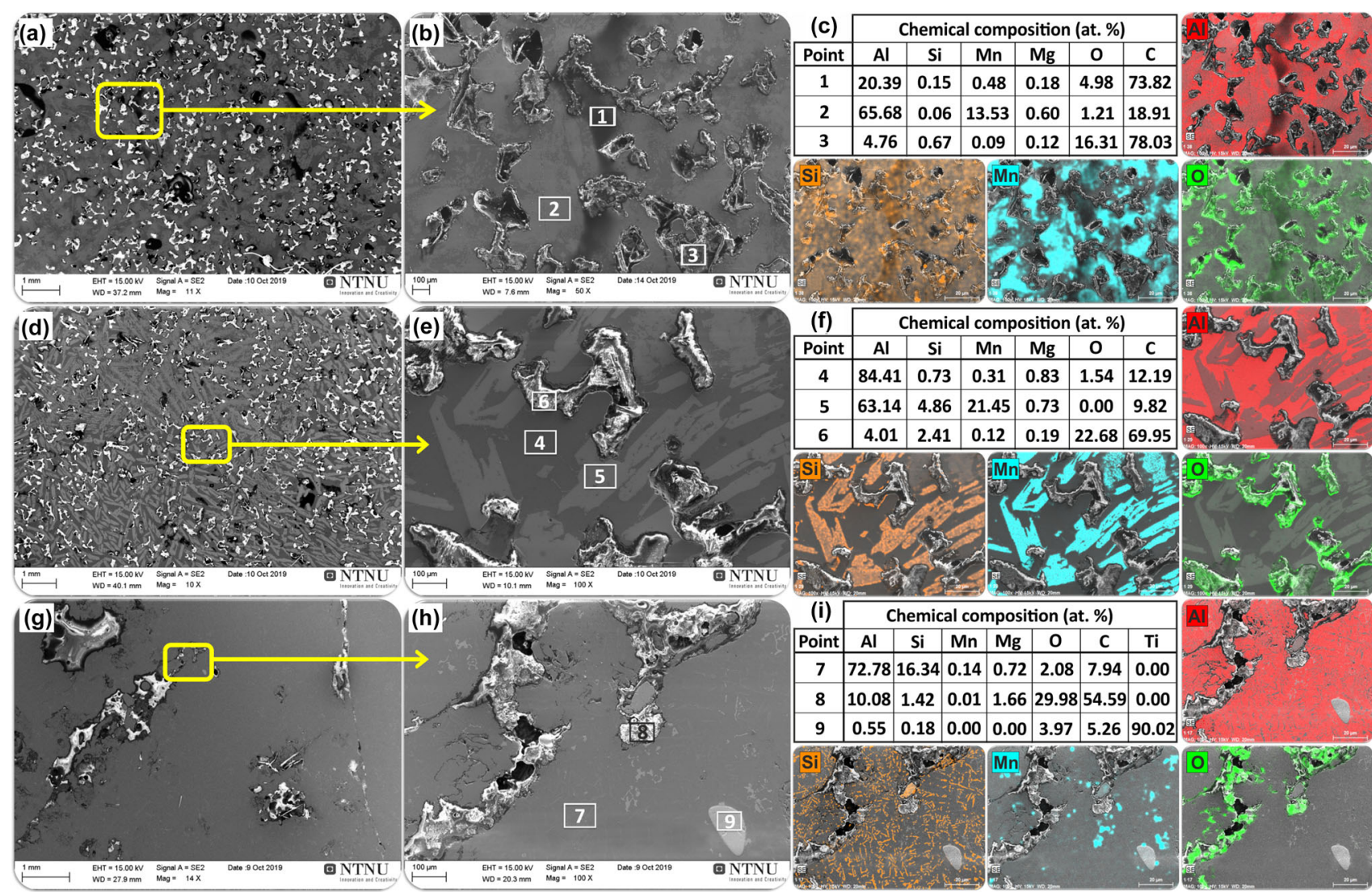

Fig 2. The results of SEM/EDS analyses of the cross-sectioned samples taken from the top $(a-c)$, middle $(d-f)$ and bottom part $(g-i)$ of the extracted Al dross. The EDS results (c, f, i) were obtained from the areas presented in (b, e, h), respectively.

of a large sample) were subjected to structural analyses.

The structure and morphology of the analyzed $\mathrm{Al}$ dross sample vary depending on the location in the sampling unit from which it was taken. The top of the sample consists mostly of $\mathrm{Al}$ and $\mathrm{Mn}$ phases, probably $\mathrm{Al}$ and $\mathrm{Al}_{12} \mathrm{Mn}$ phases regarding the $\mathrm{Al}$ Mn binary phase diagram, ${ }^{35}$ and an average of 66 at. $\% \mathrm{Al}$ and 14 at. $\% \mathrm{Mn}$ is measured for this metallic part (typically for area 2 in Fig. 2). The middle of the sample has a matrix of an $\mathrm{Al}(\mathrm{Si}, \mathrm{Mn}, \mathrm{Mg})$ solid solution consisting of around 84 at.\% Al (point 4). Point 5 identified an Al-Mn secondary intermetallic phase containing around 63 at. $\% \mathrm{Al}$ and 21 at.\% Mn. The bottom of the sample has a predominant fraction of around 73 at.\% $\mathrm{Al}$ and 16 at.\% Si needles (point 7). A metallic phase having a very high $\mathrm{Ti}$ content (90 at.\%) was also identified at point 9. A high carbon content (55 at.\%-80 at.\%) was detected by the EDS analysis in all samples (points $1,3,6,8$ ), indicating the existence of carbides regarding measured chemical compositions. However, a high localization of oxygen revealed on the EDS maps suggests that these particles could be roughly recognized as adjacent non-metallic oxide inclusions. These observations were on a few sample particles from each sample location and are relatively representative. These inhomogeneities and compositional/structural differences are of no significant importance in this work as random samples 
from the whole samples (top to bottom) were further treated.

\section{Recovery of Aluminum by Mechanical Treatment}

The results of the studies on the milling product are presented and discussed as follows.

\section{Particle Size Distribution}

Considering morphology, by milling the white $\mathrm{Al}$ dross, we changed the irregular shape of dross to a particulate material in which the large particles, i.e., $>1 \mathrm{~mm}$, were rounder and had a semi-spherical shape. The classification of the particles by size after milling indicated that $39 \%-45 \%$ of particles were $<1 \mathrm{~mm}, 3 \%-5 \%$ were $1 \mathrm{~mm}-1.25 \mathrm{~mm}, 6 \%-$ $11 \%$ were $1.25 \mathrm{~mm}-2 \mathrm{~mm}, 10 \%-15 \%$ were $2 \mathrm{~mm}-4$ $\mathrm{mm}, 14 \mathrm{~mm}-17 \mathrm{~mm}$ were $4-10 \mathrm{~mm}$ and $10 \%-25 \%>$ $10 \mathrm{~mm}$ (see supplementary Fig. S4). For the first milling trial, a fraction of $38.7 \%<1 \mathrm{~mm}$ was obtained. The second highest mass fraction was obtained for the biggest particles $(\geq 10 \mathrm{~mm})$ with $24.9 \%$, decreasing to $2.8 \%$ for the particles sized 1 $\mathrm{mm}-1.25 \mathrm{~mm}$. For the second milling trial, the largest fraction of $44.6 \%$ was obtained for the smallest particles $(\leq 1 \mathrm{~mm})$, as for the first trial. Two fractions with a particle size of $4 \mathrm{~mm}-10 \mathrm{~mm}$ and $2 \mathrm{~mm}-4 \mathrm{~mm}$ constitute the second highest mass fraction as $14.5 \%$ and $14.8 \%$ of the total material, respectively. In short, we may conclude that that $39 \%-45 \%$ of the utilized dross becomes very fine $(<$ $1 \mathrm{~mm}$ ) under the applied conditions via mechanical milling in this study.

\section{Microstructural Analysis}

The SEM/EDS microstructural analysis results for different size fractions of the milled dross are shown in Fig. 3. Analysis of the chemical composition by x-ray diffraction (XRD) of the smallest fraction with a particle size $\leq 1 \mathrm{~mm}$ is shown in Fig. 5.

It was found that the largest $\mathrm{Al}$ dross particles ( $\geq$ $10 \mathrm{~mm}$ ) consisted mostly of metallic aluminum, and the metal contained around 92 at.\% Al (area 1 in Fig. 3a). The presence of a secondary phase containing around 68 at.\% $\mathrm{Al}, 19$ at.\% $\mathrm{Mn}$ and 12 at.\% Si (area 2) was also observed. The amount of this phase was significant as seen in Fig. 3a. Based on the results of the EDS evaluations and considering the Al-Si-Mn phase diagram ${ }^{35}$, it is concluded that the chemical composition of the bright phase in area 2 in Fig. 3a corresponds to the cubic $\alpha-\mathrm{Al}_{9} \mathrm{Mn}_{2} \mathrm{Si}$ phase. For the fraction with a particle size of $4 \mathrm{~mm}-$ $10 \mathrm{~mm}$ (Fig. 3b), a phase with the structure of an $\mathrm{Al}$ ( $\mathrm{Si}, \mathrm{Mn}, \mathrm{Mg}$ ) solid solution consisting of around 91 at.\% $\mathrm{Al}$ (area 3 in Fig. 3b) has been identified. Area 4 in Fig. 3b was identified again as the above $\alpha$ $\mathrm{Al}_{9} \mathrm{Mn}_{2} \mathrm{Si}$ intermetallic phase, containing around 66 at.\% $\mathrm{Al}, 16$ at.\% $\mathrm{Mn}$ and 12 at.\% Si, which, based on the phase diagram, ${ }^{35}$ may suggest the cubic $\alpha$ $\mathrm{Al}_{9} \mathrm{Mn}_{2} \mathrm{Si}$ phase. For particle size of $2 \mathrm{~mm}-4 \mathrm{~mm}$ (Fig. 3c), the results showed the presence of the main phase of the metal matrix, containing around 87 at.\% Al (area 5 in Fig. 3c). A needle-like Si phase (area 6 in Fig. 3c) was also identified, containing around 81 at.\% $\mathrm{Si}$, and it may be $\mathrm{Si}$ particles in the $\mathrm{Al}$ matrix, since $\mathrm{Al}$ is detected. A $\mathrm{Mn}$-containing phase was also identified, containing around 12 at.\% $\mathrm{Mn}$ (area 7 in Fig. 3c), which is most likely again the cubic $\alpha-\mathrm{Al}_{9} \mathrm{Mn}_{2} \mathrm{Si}$ phase. In the particle size fraction $1.25 \mathrm{~mm}-2 \mathrm{~mm}$ (Fig. 3d), a structure containing metallic phase of around 85 at.\% $\mathrm{Al}$ (area 8 in Fig. 3d) was identified. Point 10 in Fig. 3d was identified as $\alpha-\mathrm{Al}_{9} \mathrm{Mn}_{2} \mathrm{Si}$ intermetallic phase, containing around 71 at. $\% \mathrm{Al}, 12$ at.\% $\mathrm{Mn}$ and 10 at.\% $\mathrm{Si}$, which is obviously the cubic $\alpha-\mathrm{Al}_{9} \mathrm{Mn}_{2} \mathrm{Si}$ phase. In area 9 , the Si phase was also identified, containing around 84 at.\% Si. In the particle size fraction 1 $\mathrm{mm}-1.25 \mathrm{~mm}$ (Fig. 3e), a metallic phase consisting of around 81 at.\% $\mathrm{Al}$ (area 11 in Fig. 3d) was detected. Point 12 is the Si phase containing around 88 at.\% $\mathrm{Si}$ as needles.

The comparison of the microstructures of the different size fractions of the ball-milled samples indicates that in all fractions we have metallic phases and non-metallic phases. For the metallic phases we have, however, different chemical compositions, and all analyzed metallic phases have an $\alpha-\mathrm{Al}_{9} \mathrm{Mn}_{2} \mathrm{Si}$ intermetallic phase with different amounts and morphology. The amount of $\mathrm{Al}$ in the metallic matrix decreases with decreasing particle size as graphically shown in Fig. 4. However, the amount of $\alpha-\mathrm{Al}_{9} \mathrm{Mn}_{2} \mathrm{Si}$ intermetallic phase increases. In addition, the shape of this intermetallic phase changes from singular particles in larger particles to a semi-continuous phase in the small particles. We emphasize here that these observations were made on many characterized particles, and only typical images and analysis data were presented above.

The results of structural and chemical analysis of the smallest particles $\leq 1 \mathrm{~mm}$ show that its structure mostly consists of coexisting $\mathrm{Al}$ and $\mathrm{Si}$ phases with a portion of 73 at.\% $\mathrm{Al}$ and 16 at.\% Si (area 13 in Fig. 3f), which agrees with the Al-Si binary phase diagram. ${ }^{35}$ The EDS analysis of area 14 in Fig. $3 f$ suggests the presence of the $\mathrm{Al}_{2} \mathrm{O}_{3}$ phase. The XRD analysis of this sample confirms these results according to the characterized phases in the XRD spectrum shown in Fig. 5, and both metallic $\mathrm{Al}$ and $\mathrm{Si}$ phases and $\mathrm{Al}_{2} \mathrm{O}_{3}$ phase are the dominant components. These findings confirm the SEM results above; in addition, the XRD analysis shows that the fine-milled particles also contain some aluminum nitride (AlN), which is anticipated in the $\mathrm{Al}$ dross. The $\mathrm{SiO}_{2}$ phase has also been identified in a trace amount of around $0.5 \%$. It is expected that in the analyzed dross there are also small amounts of carbide as detected by the SEM and mentioned above; however, these carbides are not detected in 

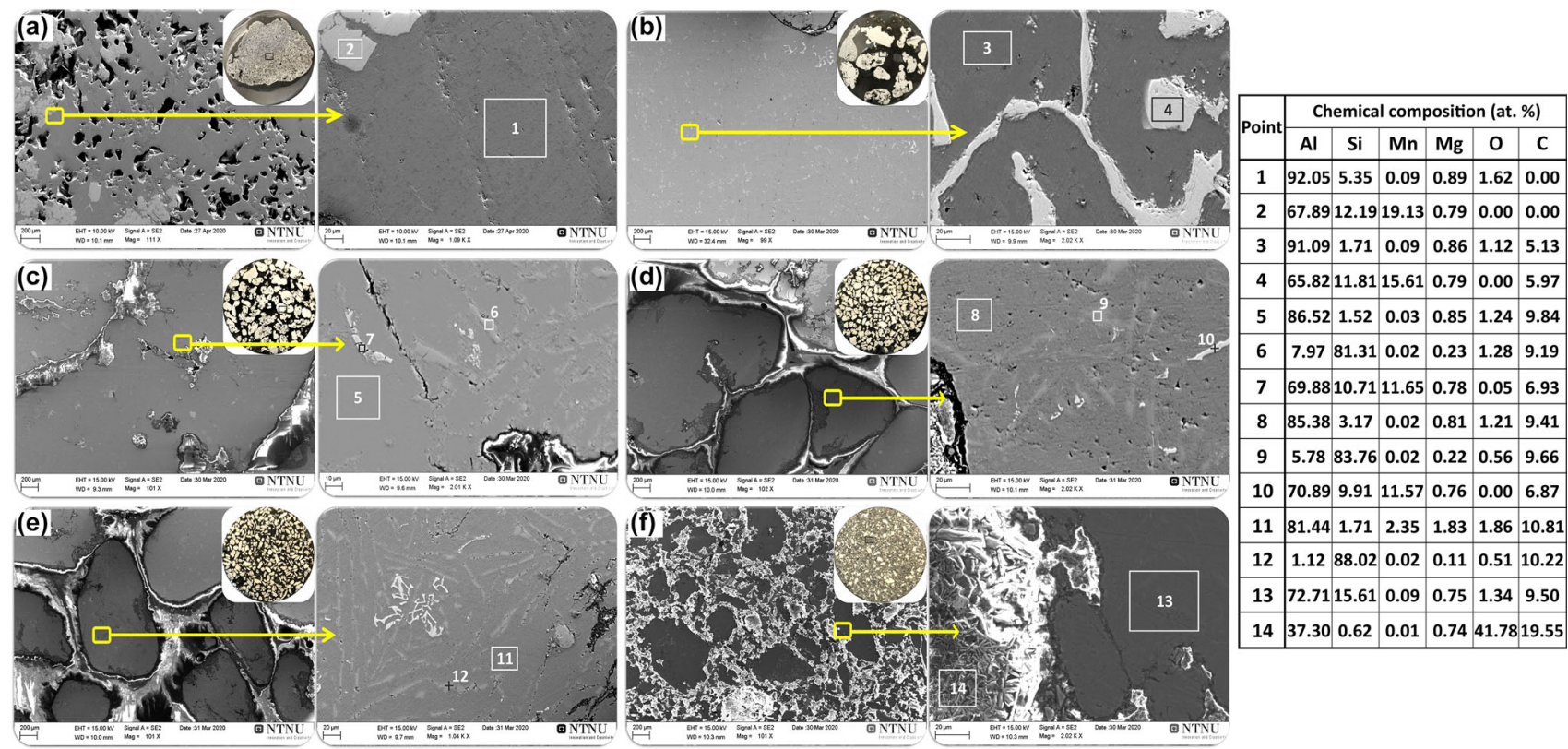

\begin{tabular}{|l|l|l|l|l|l|l|l|}
\hline 4 & 65.82 & 11.81 & 15.61 & 0.79 & 0.00 & 5.97 \\
\hline
\end{tabular} \begin{tabular}{|l|l|l|l|l|l|l|l|}
\hline 5 & 86.52 & 1.52 & 0.03 & 0.85 & 1.24 & 9.84 \\
\hline
\end{tabular} \begin{tabular}{|l|l|l|l|l|l|l|}
6 & 7.97 & 81.31 & 0.02 & 0.23 & 1.28 & 9.19 \\
\hline
\end{tabular} \begin{tabular}{|l|l|l|l|l|l|l|}
7 & 69.88 & 10.71 & 11.65 & 0.78 & 0.05 & 6.93 \\
\hline
\end{tabular} \begin{tabular}{|l|l|l|l|l|l|l|}
8 & 85.38 & 3.17 & 0.02 & 0.81 & 1.21 & 9.41 \\
\hline
\end{tabular} \begin{tabular}{l|l|l|l|l|l|l|}
9 & 5.78 & 83.76 & 0.02 & 0.22 & 0.56 & 9.66 \\
\hline
\end{tabular}

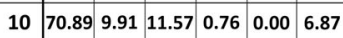
\begin{tabular}{l|l|l|l|l|l|l|}
11 & 81.44 & 1.71 & 2.35 & 1.83 & 1.86 & 10.81 \\
\hline
\end{tabular} \begin{tabular}{|l|l|l|l|l|l|l|}
12 & 1.12 & 88.02 & 0.02 & 0.11 & 0.51 & 10.22 \\
\hline
\end{tabular} \begin{tabular}{l|l|l|l|l|l|l|}
13 & 72.71 & 15.61 & 0.09 & 0.75 & 1.34 & 9.50
\end{tabular} \begin{tabular}{|l|l|l|l|l|l|l|}
14 & 37.30 & 0.62 & 0.01 & 0.74 & 41.78 & 19.55 \\
\hline
\end{tabular}

Fig 3. Results of SEM/EDS analyses of the cross-sectioned samples of the milled Al dross for particular fractions of the size: (a) $\geq 10 \mathrm{~mm}$; (b) 4 $\mathrm{mm}-10 \mathrm{~mm}$; (c) $2 \mathrm{~mm}-4 \mathrm{~mm}$; (d) $1.25 \mathrm{~mm}-2 \mathrm{~mm}$; (e) $1 \mathrm{~mm}-1.25 \mathrm{~mm}$; (f) $\leq 1 \mathrm{~mm}$.

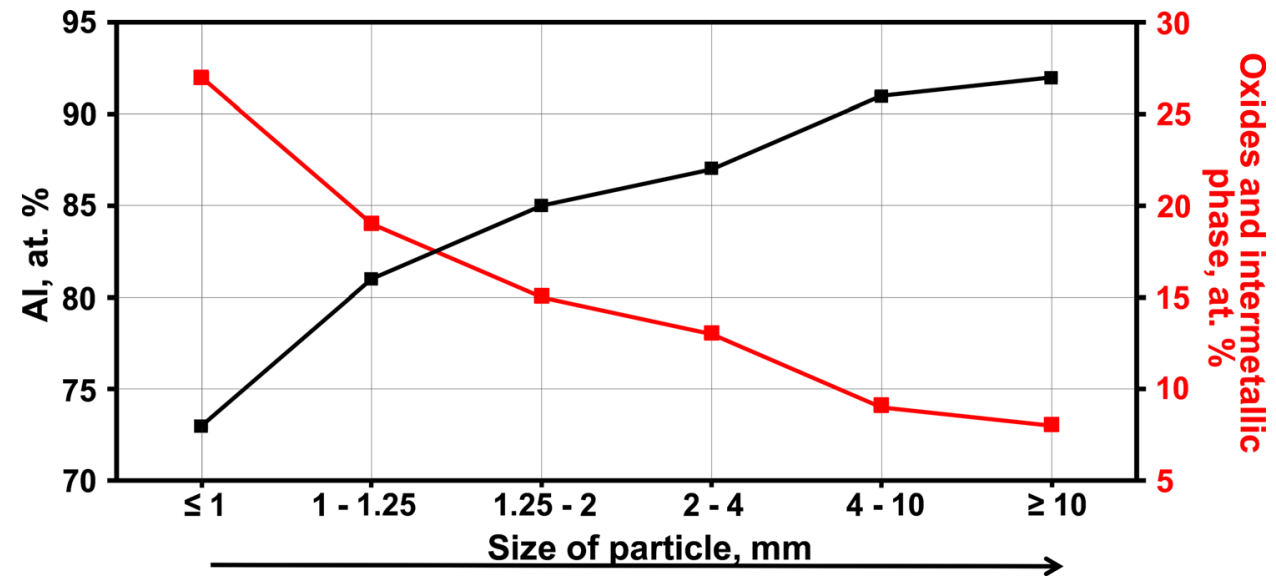

Fig 4. Distribution of the percentage of the Al metal matrix and oxygen and intermetallic phase depending on particle size.

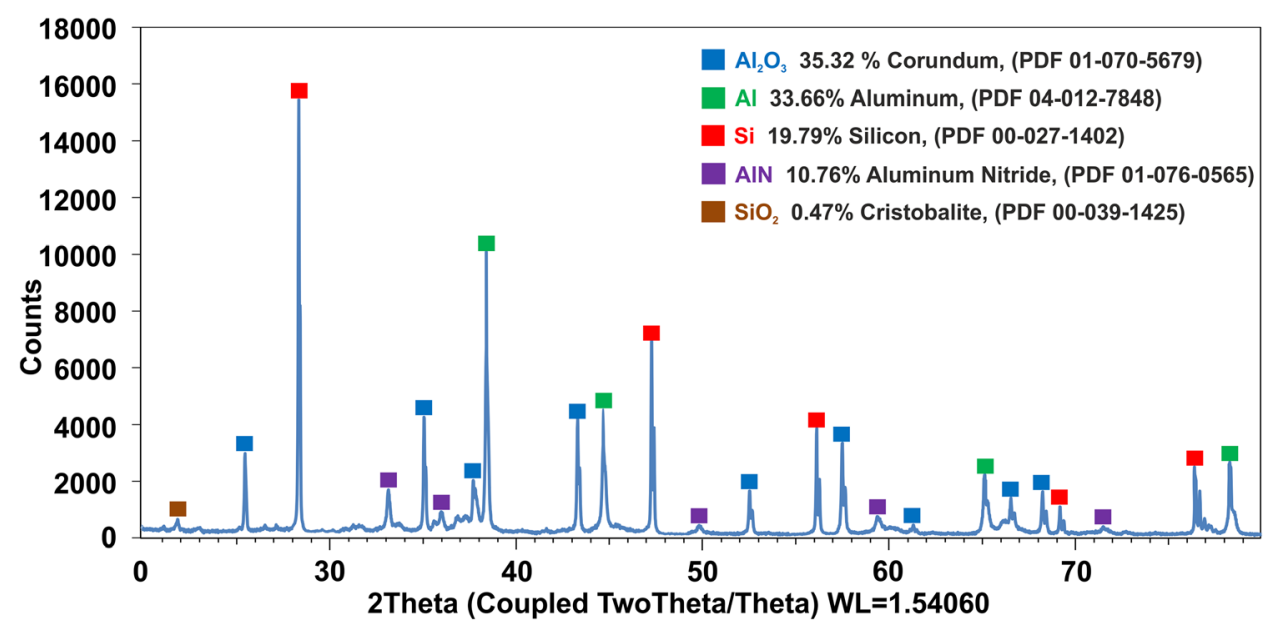

Fig 5. Results of XRD analyses of separated Al dross particles having a size $\leq 1 \mathrm{~mm}$ in the first trial on particle size. 
the XRD because of their low amount in the fine dross particles.

Considering the above results, the mechanical treatment of the dross by the ball mill has separated richer and larger metallic $\mathrm{Al}$-containing particles from the finer and richer non-metallic $\mathrm{Al}_{2} \mathrm{O}_{3}$-based particles. To evaluate the metal recovery, we applied a semi-quantitative approach here by mass balance and microstructural analysis. The results of the chemical composition analysis (Fig. 3) showed that the larger particles have an average of about $80 \%$ metallic content (excluding the oxygen content) for particle size classes $\geq 10 \mathrm{~mm}, 4 \mathrm{~mm}-10 \mathrm{~mm}$ and $2 \mathrm{~mm}-4 \mathrm{~mm}$. Considering the masses for these fractions (see supplementary Fig. S4), we obtain about $52 \%$ metal recovery by separating $\geq 2 \mathrm{~mm}$ particles. It is worth mentioning that using the ball mill and sizing by screening are the cheapest industrial processes in the mineral industry, and they do not require high capital expenses (CAPEX) and operational expenses (OPEX) compared to the other mineral processing techniques. Hence, the application of this methodology is feasible as it has been used for many years in different industries and does not require technology development or high expertise levels.

\section{Remelted Al-Rich Particles}

The obtained results on flux-free remelting of Alrich classified particles are presented and discussed as follows.

\section{Remelting Product Evaluation}

Based on the structural analysis of the $\mathrm{Al}$ dross after mechanical treatment and sieving, three fractions with the biggest particle sizes with richer and larger metallic Al-containing particles were selected for remelting; more details were given in Sect. 2 . Figure 6 shows macro-views of the materials and the crucibles before and after remelting of the fractions with particles $\geq 10 \mathrm{~mm}$ (Fig. 6a), $4 \mathrm{~mm}-$ $10 \mathrm{~mm}$ (Fig. 6b) and $2 \mathrm{~mm}-4 \mathrm{~mm}$ (Fig. 6c).

Considering the macro-views of the broken crucible after remelting, the division of the sample into two areas is possible, namely the area of the agglomerated fraction and the complete remelted fraction. The comparison of the percentage mass distribution of the agglomerated fraction with the metal fraction for particles $\geq 10 \mathrm{~mm}$, we observe that it amounts to $49 \%$ to $51 \%$, respectively. For particles $\geq 4 \mathrm{~mm}-10 \mathrm{~mm}$, the percentage mass distribution of the agglomerated fraction to the remelted fraction is $68 \%$ to $32 \%$, respectively, while of particles $\geq 2 \mathrm{~mm}-4 \mathrm{~mm}$ is $77 \%$ to $23 \%$, respectively. The comparison of the percentage mass distribution of the agglomerated and the remelted fractions for three particles sizes indicates that the completely melted fraction is decreased with decreasing particle size, while the percentage mass distribution of the agglomerated fraction is increased. Obviously, the induction remelting has upgraded the classified product of milling to some extent by homogenizing the structure of the remelted fraction, which consists mainly of a metallic matrix of the aluminum phase containing an average of 96 at.\% $\mathrm{Al}$ (areas: 1, 4, 7 in Fig. 6). The agglomeration has prevented the particles from joining to form a single melt in the crucible. This might be attributed to the role of surface aluminum oxide on the individual particles that act as a barrier. This barrier has not been a problem for the particles in the lower part of the crucible because of the higher intensity of the electromagnetic forces in this area. Also, the load from the materials from the upper part of the crucible charge to those in the lower part, and higher local temperature in the bottom than upper part of the crucible contributed to this. The agglomeration can be prevented via flux added remelting, such as the addition of salts; however, it is not the subject of this study as the intention was to develop a salt-free recycling process.
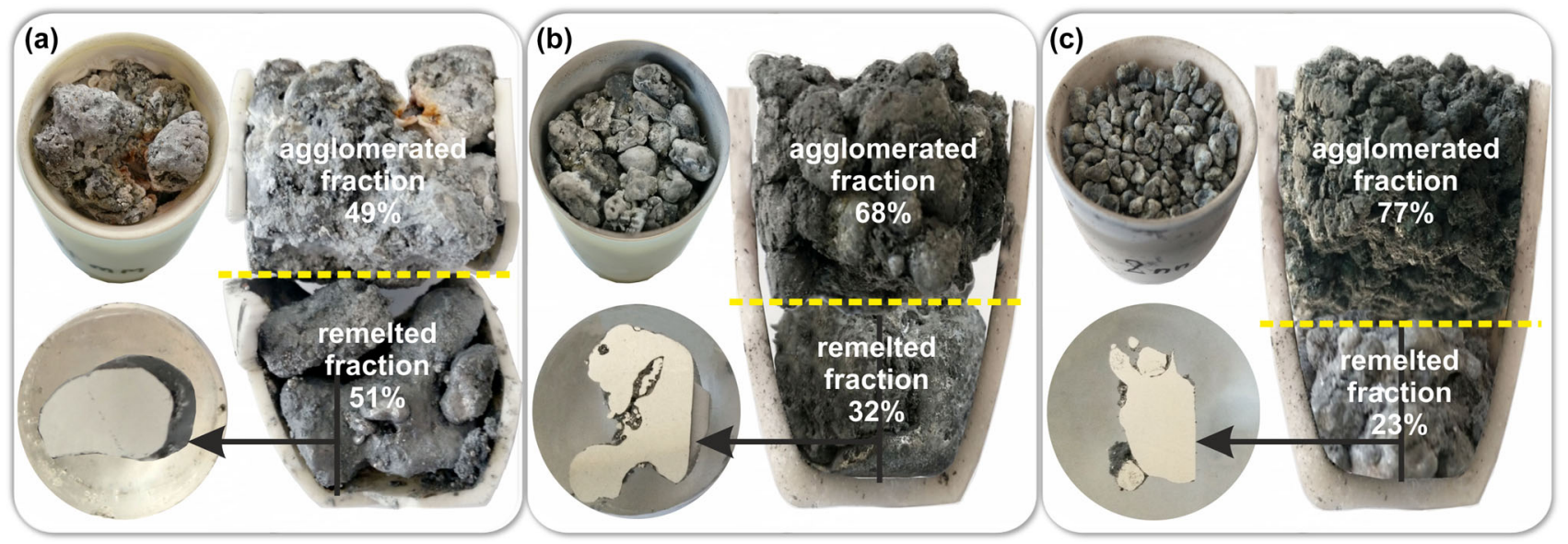

Fig 6. Views of the top (before remelting) and broken crucible after remelting of the fractions with particles: (a) $\geq 10 \mathrm{~mm}$; (b) $4 \mathrm{~mm}-10 \mathrm{~mm}$; (c) 2 $\mathrm{mm}-4 \mathrm{~mm}$. 


\section{Microstructural Analysis}

The SEM/EDS microstructural analysis results of the complete remelted fractions from the three biggest remelted particles sizes, $\geq 10,4 \mathrm{~mm}-0$ and $2 \mathrm{~mm}-4 \mathrm{~mm}$, are shown in Fig. 7 .

Microstructural analysis showed that the recovered metal via remelting of the largest particle size $(\geq 10 \mathrm{~mm}$ ) consists mostly of metallic aluminum containing around 96 at.\% $\mathrm{Al}$ (area 1 in Fig. 7b) and $\mathrm{Si}$ and Mn elements. Area 2 in Fig. $7 \mathrm{~b}$ consists of coexisting $\mathrm{Al}$ and Si phases with a portion of 79 at.\% $\mathrm{Al}$ and 18 at.\% Si. The metallic aluminum phase matrix with some $\mathrm{Si}, 91$ at.\% $\mathrm{Al}$ and 7 at.\% $\mathrm{Si}$ was identified in area 3 (Fig. $7 b$ ). For the particle size of $4 \mathrm{~mm}-10 \mathrm{~mm}$, the metallic part consists mostly of metallic aluminum matrix, like the largest particles $(\geq 10 \mathrm{~mm}$ ), and contains around 96 at.\% $\mathrm{Al}$ (area 4 in Fig. 7e). Coexisting $\mathrm{Al}$ and $\mathrm{Si}$ phases with a portion of 73 at.\% $\mathrm{Al}$ and 25 at.\% Si have been identified in area 5 (Fig. $7 \mathrm{e}$ ). In point 6 , the $\mathrm{Si}$-Al phase was also identified, containing around 85 at. $\% \mathrm{Si}$ and 13 at.\% $\mathrm{Al}$. For the particle size of $2 \mathrm{~mm}-4 \mathrm{~mm}$, like in the previous two samples, the metallic fraction consisted mostly of metallic aluminum phase matrix, containing around 95 at.\% $\mathrm{Al}$ (area 7 in Fig. 7h). Point 8 in Fig. $7 \mathrm{~h}$ was identified as $\alpha-\mathrm{Al}_{9} \mathrm{Mn}_{2} \mathrm{Si}$ intermetallic phase, containing around 78 at.\% $\mathrm{Al}$, 14 at.\% Si and 7 at.\% Mn. In addition, a Si-rich phase was also identified in point 9 in Fig. $7 \mathrm{~h}$, containing around 96 at.\% $\mathrm{Si}$, and it is metallic $\mathrm{Si}$ particle in $\mathrm{Al}$ matrix.

The applied process shows that the upgrading of white dross is possible through mechanical treatment, followed by classification and remelting of the metal-rich larger particles. The produced metal contains metallic phases and small amounts of oxygen. This oxygen may be due to some surface oxidation of the SEM samples during preparation.

\section{AL RECOVERY FROM THE WHITE DROSS}

According to the obtained results in this study, we may propose that the white dross can be treated via the illustrated process in Fig. 8. In this process the dross is mechanically treated, for instance by a ball mill as in this study, and then is classified according to the size of the particles. This step can be considered as a dross beneficiation part and can be more effectively and economically done on cold dross. As we showed in this study, we obtain two group of products from this step: metal-rich and metal-poor products. The Al-rich product can be remelted for $\mathrm{Al}$ recovery or recycled into the reverberatory furnace, and the metal-poor product, which contains oxides, nitrides, carbides and phosphides, is subjected to further treatment in the secondary $\mathrm{Al}$ production.
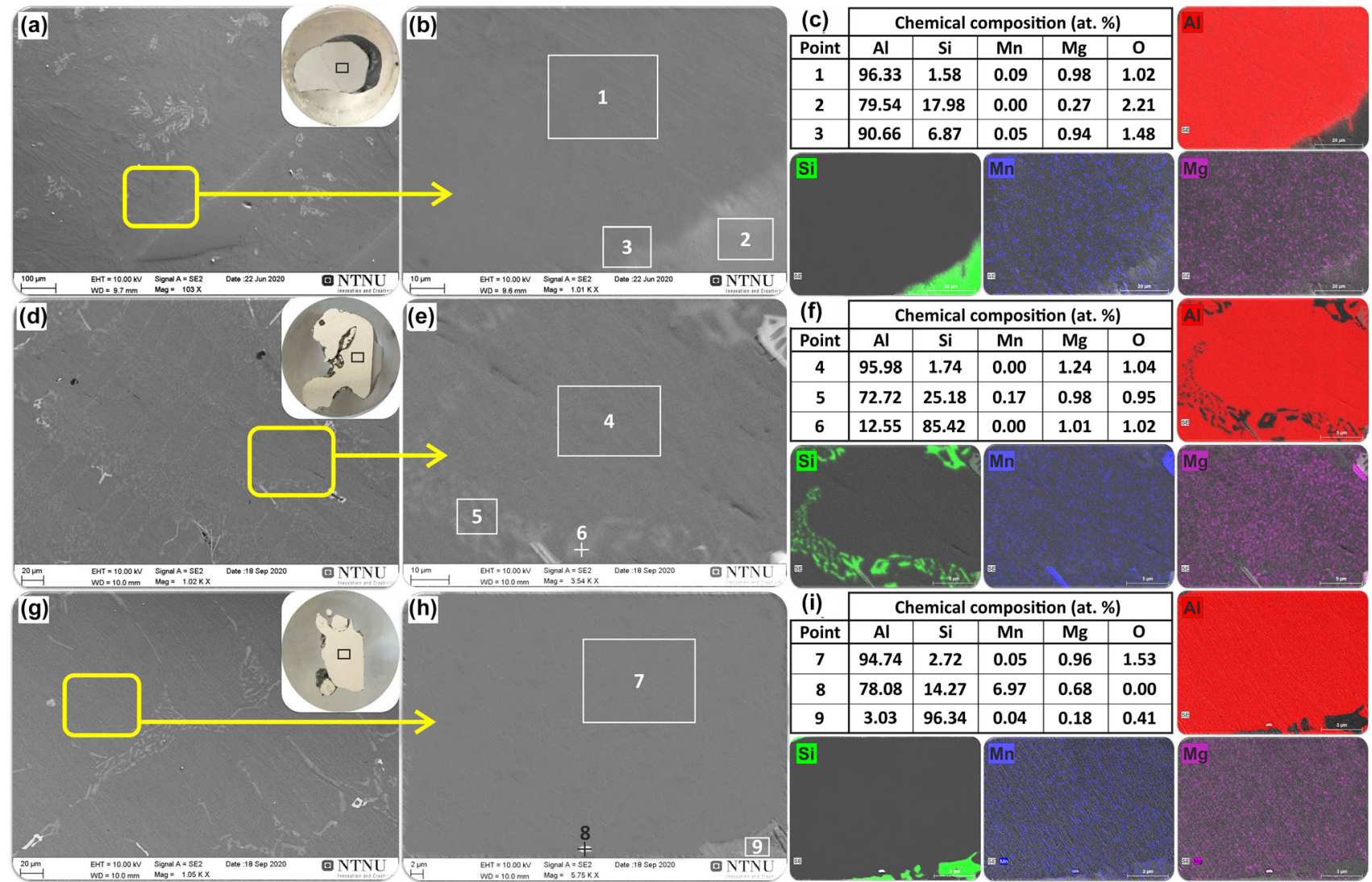

Fig 7. The results of SEM/EDS analyses of the cross sections of completely melted fractions from remelted particle size $\geq 10 \mathrm{~mm}$ (a-c), 4-10 mm $(d-f)$ and 2-4 $\mathrm{mm}(\mathrm{g}-\mathrm{i})$. The EDS results $(\mathrm{c}, \mathrm{f}, \mathrm{i})$ were obtained from the areas presented in $(b, e, h)$, respectively. 


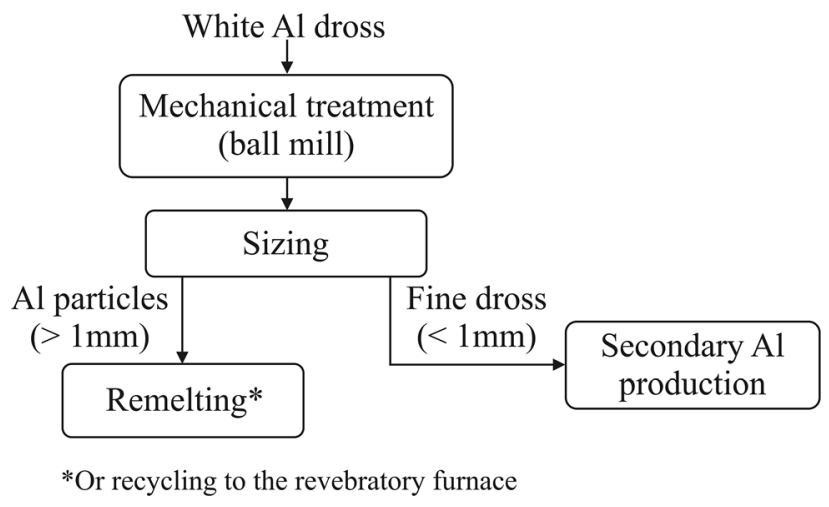

Fig 8. Flow sheet of the proposed treatment of white dross for Al recovery.

The recent published work by the authors showed that the rich $\mathrm{Al}$ particles can be recycled via their use for the reduction of manganese oxide from waste from the ferromanganese industry, which yields AlMn alloys. ${ }^{36}$ In this process, a large portion of the $\mathrm{Al}$ in the dross particles is distributed into the produced alloy, and the rest is consumed to reduce manganese oxide $(\mathrm{MnO})$. The non-metallic components are removed via an oxide slag byproduct, without any salt use. This Al-Mn alloy can be recycled in the $\mathrm{Al}$ industry for making $\mathrm{Mn}$-containing $\mathrm{Al}$ alloy grades. ${ }^{36}$

\section{CONCLUSION}

The $\mathrm{Al}$ recovery from white dross was studied by experimental work via mechanical treatment followed by the induction remelting of the produced Alrich particles. The following conclusions are summarized from this work:

1. The mechanical treatment of the $\mathrm{Al}$ dross by a ball mill allows for separation of richer and larger metallic $\mathrm{Al}$-containing particles from the finer and richer $\mathrm{Al}_{2} \mathrm{O}_{3}$-containing particles.

2. The purity of the Al metal matrix is decreased with decreasing particle size in the milled dross.

3. The larger particles of $\mathrm{Al}$ dross after mechanical treatment contain about $80 \%$ metallic portions.

4. After remelting of larger particles, two areas can be observed in the samples: (1) the agglomerated fraction and (2) the melted fraction. The melted fraction consists mostly of the metallic aluminum phase matrix, containing an average of about 96 at.\% $\mathrm{Al}$.

5. The remelting of richer Al-containing dross particles yields more homogeneous and inclusion-free metal.

\section{ACKNOWLEDGEMENTS}

This publication has been funded by SFI Metal Production (Centre for Research-based Innovation, 237738). The authors gratefully acknowledge the financial support from the Research Council of
Norway and the partners of the SFI Metal Production.

\section{FUNDING}

Open access funding provided by NTNU Norwegian University of Science and Technology (incl St. Olavs Hospital - Trondheim University Hospital).

\section{CONFLICT OF INTEREST}

On behalf of all authors, the corresponding author states that there is no conflict of interest. The authors declare that they have no known competing financial interests or personal relationships that could have appeared to influence the work reported in this paper. The authors declare the following financial interests/personal relationships which may be considered as potential competing interests.

\section{OPEN ACCESS}

This article is licensed under a Creative Commons Attribution 4.0 International License, which permits use, sharing, adaptation, distribution and reproduction in any medium or format, as long as you give appropriate credit to the original author(s) and the source, provide a link to the Creative Commons licence, and indicate if changes were made. The images or other third party material in this article are included in the article's Creative Commons licence, unless indicated otherwise in a credit line to the material. If material is not included in the article's Creative Commons licence and your intended use is not permitted by statutory regulation or exceeds the permitted use, you will need to obtain permission directly from the copyright holder. To view a copy of this licence, visit $h$ ttp://creativecommons.org/licenses/by/4.0/.

\section{SUPPLEMENTARY INFORMATION}

The online version contains supplementary material available at https://doi.org/10.1007/s11837021-04730-x.

\section{REFERENCES}

1. P.E. Tsakiridis, J. Hazard. Mater. 217, 1. (2012).

2. Ph. Mandin, R. Wüthrich, and H. Roustan, ECS Trans. 19, 1. (2009).

3. World Aluminum (International Aluminum Institute, 2019), http://www.world-aluminum.org/statistics/. Accessed 25 Jan 2021.

4. S.O. Adeosun, O.I. Sekunowo, O.O. Taiwo, W.A. Ayoola, and A. Machado, Adv. Mater. 3, 6. (2014).

5. S.K. Verma, V.K. Dwivedi and S.P. Dwivedi, Mater. Today Proc. (2021). https://doi.org/10.1016/j.matpr.2020.12.045. Accessed 25 Jan 2021.

6. O. Manfredi, W. Wuth, and I. Bohlinger, JOM 49, 48. (1997).

7. D.B. Masson, and M.M. Taghiei, Mater. Trans. 30, 411. (1989). 
8. K.N. Maung, T. Yoshida, G. Liu, C.M. Lwin, D.B. Muller, and S. Hashimoto, Resour. Conserv. Recycl. 126, 34. (2017).

9. M.C. Shinzato, and R. Hypolito, Environ. Earth Sci. 75, 628. (2016).

10. B. Lucheva, T. Tsonev, and R. Petkov, J. Univ. Chem. Technol. Metallurgy 40, 335. (2005).

11. P.E. Tsakiridis, P. Oustadakis, and S. Agatzini-Leonardou, J. Environ. Chem. Eng. 1, 23. (2013).

12. C. Dai, and D. Apelian, J. Sustain. Metall. 3, 230. (2017).

13. S. Maropoulos, D. Kountouras, X. Voulgaraki, S. Papanikolaou, and I. Sanaidis, Adv. Tribol. 2011, 1697. (2011).

14. A.M. Amer, JOM 54, 72. (2002).

15. A. Meshram, and K.K. Singh, Resour. Conserv. Recycl. 130, 95. (2018).

16. V. Kevorkijan, JOM 54, 34. (2002).

17. A. Gil, and S.A. Korili, Chem. Eng. J. 289, 74. (2016).

18. E. Gomez, D.A. Rani, C.R. Cheeseman, D. Deegan, M. Wise, and A.R. Boccaccini, J. Hazard. Mater. 161, 614. (2009).

19. J.A. Soares Tenorio, and D.C. Romano Espinosa, J. Light Met. 2, 89. (2002).

20. N. Ünlü, and M.G. Drouet, Resour. Conserv. Recycl. 36, 61. (2002).

21. M.I. Boulos, Pure Appl. Chem. 68, 1007. (1996).

22. B.I. Abdulkarim, M.A. Abu Hassan, and A.M. Ali, AJET 4, 92. (2016).

23. S. Espiari, F. Rashchi, and S.K. Sadrnezhaad, Hydrometallurgy 82, 54. (2006).

24. B. Dash, B.R. Das, B.C. Tripathy, I.N. Bhattacharya, and S.C. Das, Hydrometallurgy 92, 48. (2008).

25. A.M. Amer, JOM 62, 60. (2010).

26. B.R. Das, B. Dash, B.C. Tripathy, I.N. Bhattacharya, and S.C. Das, Miner. Eng. 20, 252. (2007).
27. M.S.R. Sarker, M.Z. Alam, M.R. Qadir, M.A. Gafur, and M. Moniruzzaman, Int. J. Miner. Metall. Mater. 22, 429. (2015).

28. H.A. Gill, An Improved Method of Utilizing Aluminium Skimmings, Screenings, Slags and analogous Materials. (GB Patent Documents, No 114,204A, 1918), https://patent s.google.com/patent/GB114204A/en?oq=GB+114\%2c204. Accessed 25 Jan 2021.

29. A. Businger, Method of and installation for processing dross of non-ferrous metals (US Patent Documents, No 3,037,711A, 1962), https://patents.google.com/patent/U S3037711A/en?oq=US+3\%2c037\%2c711. Accessed 25 Jan 2021.

30. Alton T. Tabereaux, Ray D. Peterson, Treatise on Process Metallurgy Vol. 3, Chapter 2.5 - Aluminum Production, ed. S. Seetharaman (Oxford, OX: Elsevier, 2014), p. 906.

31. T.T.N. Nguyen, M.S. Lee, and T.H. Nguyen, Processes 6, 29. (2018).

32. H. Feng, G. Zhang, Q. Yang, L. Xun, S. Zhen, and D. Liu, Processes 8, 1269. (2020).

33. X. Zhu, Q. Jin, and Z. Ye, J. Clean. Prod. 277, 123291. (2020).

34. T.T.N. Nguyen, S.J. Song, and M.S. Lee, J. Mater. Res. Technol. 9, 2568. (2020).

35. V. Raghavan, J. Phase Equilib. Diffus. 33, 140. (2012).

36. A. Kudyba, S. Akhtar, I. Johansen, and J. Safarian, Materials 14, 356. (2021).

Publisher's Note Springer Nature remains neutral with regard to jurisdictional claims in published maps and institutional affiliations. 